\title{
Toward Sustainable and Smart Cities in Africa: A Review and Challenges
}

Maria José Palma dos Santos,

Escola Superior de Comunicação Social, Instituto Politécnico de Lisboa, msantos@escs.ipl.pt

\section{Keywords}

Sustainability; Africa; Development challenges; Smart cities.

\begin{abstract}
This paper aims to present the main challenges to overcome in order to have sustainable and smart cities in Africa in the future, by analyzing social, economic, environmental, and political problems in African regions/cities.

This study is particularly relevant as the problems of sustainable development in this region and the task of finding the solutions to minimize them became world problems, since they will affect the world sustainable development. It is also important to note that although there are many studies in the scientific field of smart cities, few of them had analyzed the topic of smart cities and sustainability and none of them so far analyzed the complex situation in African cities nor brought to the scientific debate and forecast new insights about these topics. The holistic approach was used to analyze sustainable and smart cities in Africa is believed to be the first of its kind and hence has not been, to the best of our knowledge, produced elsewhere. This paper gives insights to stakeholders and public decision-makers about the way forward in the promotion and development of cities in Africa in a sustainable way, in order to foster research in these innovative areas. It also broadens new research opportunities to explore and bring more knowledge in smart sustainable cities in general and in Africa in particular.

There are many situations that require the development of the African cities to become smart and sustainable (Höjer \& Wangel, 2015). This paper considers the unprecedented and often unforeseen economic, political, social, and environmental changes with direct impacts on the urban environment in the world and in Africa in particular. The political instability in some countries, unfavorable economic conditions, economic volatility in the energy sector and climate changes, these factors all combined led to migratory movements to the cities, causing in part the massive growth of the population. On a context of poverty, this restrains the sustainable development, creating a main problem that reinforces the necessity to promote the
\end{abstract}


sustainable development (Bibri \& Krogstie, 2017). Despite these problems are already being researched, the field of smart sustainable cities is still in its early stages of development (Dos-Santos and Mota, 2019).

In order the cities in Africa move toward smartness in the future, it is necessary to previously solve problems of sustainability which nowadays affect them.

In order to address the critical issue of whether smart city policy leads to sustainability of cities, the paper focuses on explaining if smart cities bring sustainability to African cities in terms of economic, social, political, and environmental impacts or if the analysis must be done in the opposite way (Dos-Santos and Mota, 2019; Fisher \& Rucki, 2017). The paper also focuses on clarifying the main factors that lead to sustainability and smartness of African cities. These questions will be explained and clarified through these methods: analyzing the main economic, social, and environmental problems in the main urban region of Africa; analyzing the current state of the art literature about the topics of urban development, smart cities, and smart sustainable cities; analyzing if the actual developments concerned about smart cities and sustainability are adjusted to African cities; understanding the main social, economic, and environmental problems in African cities that can compromise the long-term sustainable development and smartness.

The data of regions of Northern Africa, Western Africa, Eastern Africa, Central Africa and Southern Africa was analyzed in order to point out the main challenges of social, economic, environmental, and political problems in African regions/cities (Fann et al., 2015; Yigitcanlar, \& Kamruzzaman, 2018).

After showing the analyzed data, the concepts of smart cities, sustainability and urban sustainability are explained accordingly with the verified situations in these various Africa regions, in order to provide better contextualization for this study according to Laros \& Jones, (2014) and World Bank (2018) United Nations (2015).

To each analyzed region, there are main aspects to highlight:

In Northern Africa, the major issues to point out were: a great population number, low income, young unemployment, exclusion, low professional skills and education and social struggle with migration and refugees.

Western Africa is the most rapidly urbanizing sub-region. Although there are gaps in urban data availability and reliability, it was noted that emerging urban middle classes in the sub-region are key to sustaining growth and foreign direct investment. There is a lack of regional and local urban infrastructure, logistics and transport, port infrastructure, information and communications technologies (ICT) and energy. Climate change and political instability also 
hold back the sustainable development.

Eastern Africa

-region. It has regional economic vulnerabilities and cities exhibit high levels of poverty and inequality. Climate change hold back the region development because it relies mainly in agriculture. food insecurity and inter-communal violence contribute to internal displacement and refugee flows (DosSantos and Mota, 2019).

Central Africa is urbanizing fast, but it is characterized by deep poverty, inequality and low rate of unemployment in some of the sub-

change, deforestation and a corrupted political system, in which municipalities are largely unable to collect revenues to finance their services.

Southern Africa is the most urbanized region in sub-Saharan Africa. Despite the growth of gross domestic product (GDP), there is still inequality and poverty in Southern African cities. Climate change and food insecurity are other problems that can be minimized with encouragement of non-polluting forms of urban and peri-urban agriculture and forestry.

The analysis of all the problems on the African continent shows that it is still difficult in most of these cases and urban regions to promote and develop smart cities. However, if we do not move toward good urban management and sustainability in all its dimensions,

problems will tend to increase, and development will be a more distant target.

The results presented for the different urban/rural regions of Africa show that despite the diversity of social, economic, environmental, and political problems, there is a matrix, practically common in all regions of the African continent. This common problem involves serious social, economic, and environmental risks stemming from the phenomenon of climate change, and safety and food subsistence may be even more important, which will further widen the development gap and long distance of smart cities and sustainable development. Programs of technology transfer and development aid by developed countries will therefore play a key role in this region.

The main results confirm the importance of minimizing the problems of sustainable development on the African continent; otherwise, the developed world will suffer the impacts in the future. It is also clear that the development of smart cities needs a long way in the direction of sustainable development. In other words, prior to the development of smart cities, it will be necessary in Africa to create an environment that provides development in a sustainable way. Only in this way, reducing and minimizing social, economic, and environmental gaps will be possible in the future to build smart and sustainable cities. 


\section{References}

Bibri, S. E., \& Krogstie, J. (2017). Smart sustainable cities of the future: An extensive interdisciplinary literature review. Sustainable Cities and Society, 31, 183-212.

Dos-Santos, Mota, M. (forthcoming, 2019). Toward Sustainable and Smart Cities in Africa: A Review and Challenges. In: Bioclimatic Architecture in Warm Climates. Springer Nature.

Fann, N., Nolte, C. G., Dolwick, P., Spero, T. L., Brown, A. C., Phillips, S., \& Anenberg, S. (2015). The geographic distribution and economic value of climate change-related ozone health impacts in the United States in 2030. Journal of the Air \& Waste Management Association, 65(5), 570-580.

systems approach to understanding the nexus of conflict, development and the environment. Sustainable Development, 25(4), 267-275.

Höjer, M., \& Wangel, J. (2015). Smart sustainable cities: definition and challenges. In ICT innovations for sustainability (pp. 333-349). Springer.

Yigitcanlar, T., \& Kamruzzaman, M. (2018). Does smart city policy lead to sustainability of cities?. Land Use Policy, 73, 49-58.

United Nations. (2015). World urbanization prospects. the 2014 revision. New York: Department of Economic and Social Affairs.http://esa.un.org/unpd/wup/Publications/Files/WUP2014-Report.pdf （Accessed 22.7.2018).

World Bank (2018) World Bank Database. https://data.worldbank.org/ (Retrived on $12 / 07 / 2018)$. 